\title{
カーボンナノチューブ応用二次元ひずみ分布計測センサの試作*
}

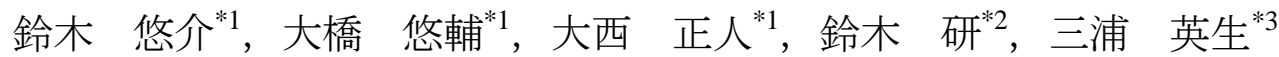

\section{Two-Dimensional Strain Distribution Sensor Using Carbon Nanotubes}

\author{
Yusuke SUZUKI ${ }^{* 1}$, Yusuke OHASHI, Masato OHNISHI, Ken SUZUKI and Hideo MIURA \\ ${ }^{* 1}$ Department of Nanomechanics, Graduate School of Engineering, Tohoku University \\ 6-6-11-716, Aoba, Aramaki, Aoba-ku, Sendai, 980-8579
}

\begin{abstract}
A new highly sensitive strain measurement method has been developed by applying the change of the electronic conductivity of CNTs, which is caused by the distortion of the electronic band structure. A two-dimensional strain distribution sensor was developed by using thin-film processing. Finely area-arrayed multi-walled carbon nanotubes (MWCNTs) were grown on a silicon wafer by applying a chemical vapor deposition method, and the area-arrayed MWCNTs were interconnected by the lift-off process of titanium thin film. The height of the grown MWCNT was about $250 \mu \mathrm{m}$, and size of the bundle of the grown CNT was $40 \mu \mathrm{m}$ square, and the pitch of the bundle was $1000 \mu \mathrm{m}$. Uni-axial pressure was applied to the sensor, and it was found that the gauge factor of the developed sensor was about 100. Thus, this sensor is usefull for detecting the two-dimensional distribution of compressive strain in micro-scale.,
\end{abstract}

Key Words : Reliability, Strain Measurement, Nondestractive Evaluation, Carbon Nanotube, Electronic Conductivity

\section{1. 緒言}

21 世紀の安全・安心な社会構築を推進するためには, 種々の構造機器の健全性を保証, 維持することが不可欠 である.しかし，システムの高機能，高性能化に伴い，高速や高温等の使用環境における負荷は厳しくなる一方 である.したがって，このような機器の破壞を的確に予知し防止するためには，従来の定期的な非破壊検查のみ では必ずしも十分ではなく, 機器に作用している実働負荷を実時間で計測・評価できることが望ましい. さらに, 各種機器の構造の微細化や複雑化に起因して, ひずみ計測の空間分解能の向上や高感度化, あるいは破壊箇所の 事前予測が難しい場合には任意の位置のひずみ分布計測など, 多様な計測ニーズが発生している.このため, 非 破壊で対象物表面近傍の負荷を計測する新たな技術開発が望まれている(1)-(10).

そこで著者らは, 機械的強度, 化学的安定性, 軽量性などで従来の物質にない優れた特性を持つカーボンナ, チューブ（CNT: Carbon Nanotube）に着目し，任意の凹凸表面にも適用可能な非破壊・非接触ひずみセンサ技術 の開発を進めている(11)-(12). これまでに, 密度汎関数法を用いて単層CNT（SWCNT: Single-walled CNT）における 電気伝導のひずみ依存性を検討し，CNT を構成する基本構造である炭素六員環が，異方的にひずむことでその電 子バンド構造にも複雑な変化が生じ，金属的な伝導特性と半導体的な伝導特性との間で負荷ひずみに依存して伝 導特性が複雑に変化することを明らかにしてきた. 結果として CNT の長軸方向に屈曲変形などの複雑な変形が 生じると, CNT 全体の電気伝導特性にも大きな変化が生じ, 高感度ひずみセンサとして応用できる可能性なども 示してきた．また，樹脂中に多層 CNT（MWCNT: Multi-walled CNT）を分散させて試作したひずみセンサで最大 ゲージ率 400 も実現し, 超高感度ひずみセンサの実現可能性を示すとともに，ゴム中に分散させることで大変形 ひずみの計測可能性なども示してきた.さらに，このような大きな抵抗值変化はマイクロ波等を応用して計測可 能であり，非接触ひずみ計測も可能となることを示してきた．本研究では，多層 CNT を二次元アレイ状に配列 させた二次元ひずみ分布センサの試作とその感度評価について検討した概要を報告する.

\footnotetext{
* 原稿受付 2011 年 10 月 31 日

*1 学生員, 東北大学 大学院工学研究科ナノメカニクス専攻（†980-8579 宮城県仙台市青葉区荒巻字青葉 6-6-11-716)

*2 正員, 東北大学 大学院工学研究科 附属エネルギー安全科学国際研究センター

*3 正員, フェロー, 東北大学 大学院工学研究科 附属エネルギー安全科学国際研究センター

E-mail: hmiura@rift.mech.tohoku.ac.jp
} 


\section{2. 異方的変形に伴う CNT 電子バンド構造の変化}

CNT が屈曲変形した場合の電子バンド構造変化を解析的に検討した．しかし，CNT の電気伝導性を解析的 に解明するためには, CNT のカイラリティ, 屈曲, 層数などを考慮する必要があり, 解析モデルが大型化し, 膨 大な解析時間がかかる. そこで本研究では，CNT の基本物性を支配していると考えられる，グラフェンシートの 電気伝導特性ひずみ依存性から CNT の局所的な電気伝導性の変化を予測することを試みた．図 1 に示すような 解析モデルの六員環を変形させ，バンド構造の変化を Tight-binding 法を応用した第一原理解析手法を用いて検討 した ${ }^{(13)-(15)}$. 図 2 に示すように負荷と平行方向の炭素間結合距離と, 負荷と傾斜した方向の炭素間の結合距離をそ れぞれ $\mathrm{a}, \mathrm{b}$ とした．まず，一軸負荷を作用した場合を想定し， $\mathrm{a}=1.42 \AA$ で固定し， b のみを変化させた際のバ ンドギャップ変化を解析した結果を， b/a の関数としてまとめ図 2 に示寸. なお本解析において，六員環の内角 は $120^{\circ}$ 一定で固定した. 本図より, 六員環の対向した頂点を軸とする方向に結合が引き延ばされた場合 (図中 では b/a の值が減少した場合), 約 7\%以上の変化でバンドギャップが発生することが明らかになった．また，対 向した結合辺方向を軸とした方向に結合が引き延ばされた場合（図中では b/a の值が増加した場合）には, 顕著 なバンドギャップ変化を示さないことから, 負荷方向に依存してグラフェンシートの電気伝導特性の変化にも多 様性が生じる事も明らかになった.

次に，この解析結果に基づき，一軸負荷に加えて静水圧負荷を想定した相似形状解析を行った結果も同様に図 4 中に示寸. 本解析では, a を固定した六員環を元に, 六員環の形状は相似形のまま維持し (b/a 一定), 静水圧 による絶対值の変化によるバンドギャップヘの影響を検討している．絶対值の変動範囲は土20\%とした．六員環 が正六角形（b/a=1）を保持している場合には，バンド構造に顕著な変化は現れず，金属伝導特性が維持されるこ とが分かる．しかし，b/a の值が 1 からずれるほど静水圧の影響が顕在化し，b/a 值が一定でも電気伝導特性は金 属的なものから半導体的なものまで大きく変化することが明らかになった．したがって, CNT の電気伝導特性に は，等方的な静水圧が作用する効果と面内二軸異方的な垂直応力場が作用する効果の二種類の負荷が影響するこ とが明らかになった.このように，グラフェンシートの電気伝導特性は金属的な伝導特性から半導体的な伝導特 性に大きく変化する可能性が示された.

したがって, グラフェンシートを巻いた構造となっているCNT においても, 屈曲変形が生じ, 炭素の六員環 に複雑な変形が生じるような場合には, CNT の電気伝導特性が局所的に著しく変化することが予想される. 特に CNT の軸方向に圧縮負荷が作用寸る場合には，CNTに局所的な座屈変形が生じ，その周辺では当然炭素六員環 の形状が複雑に変形寸ることは容易に想定される。一般的に, 単層 CNT はカイラリティと呼ばれるグラフェン シートを巻く結晶方位に依存して，半導体的な性質（確率論的に 2/3）を持つものと金属的な性質（確率論的に 1/3）を持つものが混在する, 多層 CNT を構成する各単層 CNT の電気伝導特性がこのような確率論的分布になっ ているものとし，少なくても 1 層の CNT が金属的な伝導特性を持つ場合に MWCNT 全体が金属的な伝導特性を 示すものと仮定すると，10 層以上からなる MWCNT は実質的に金属的な伝導特性を示すと考えてよい. この場

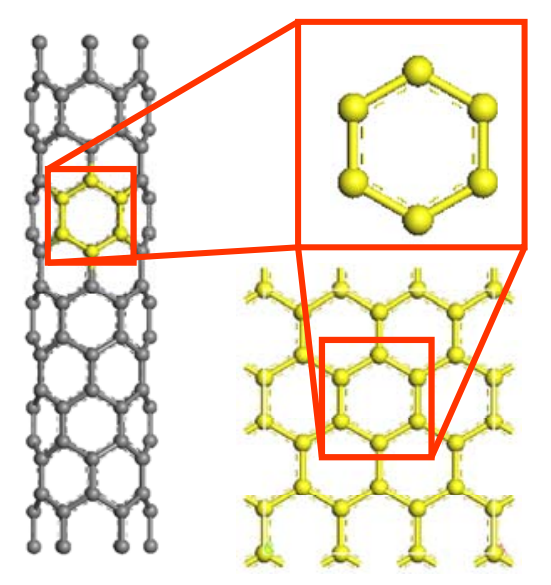

Fig. 1 Analytical model of a grapheme sheet for the first principle calculation

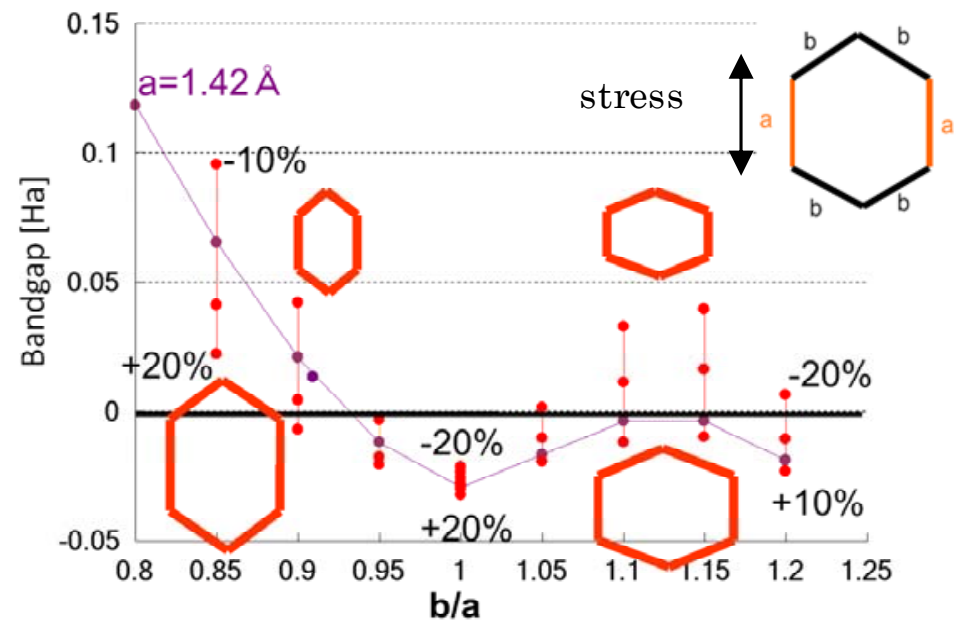

Fig. 2 Effects of anisotropic deformation and hydrostatic pressure of a deformed graphene sheet 
合, MWCNT の軸方向に圧縮ひずみを作用させ，炭素六員環に図 2 に示すような半導体的なバンド構造を呈する ような変形を生じさせると, 大きな抵抗変化（増加）が生じることが期待でき, 超高感度なひずみ（圧力）セン サの実現が可能となるものと考えられる.

\section{3. 二次元ひずみ分布計測センサの試作}

図 3 にセンサの試作工程概要図を示す，二次元のひずみ分布計測を可能とするため，本研究では薄膜加工技術 を応用し，上下で直交する配線層間に MWCNT をエリアアレイ上に配列させた構造を直径 2 インチの単結晶シ リコン基板上に作製した.

まず, 表面を熱酸化した単結晶シリコン基板上にスパッタ法で $\mathrm{Ti}$ を堆積し, 下層配線となる薄膜配線パターン を形成した. その後形成した Ti 配線上に, MWCNT を成長させる触媒ともなる鉄微粒子をアークプラズマ法で堆 積させた．この場合，堆積させる鉄の薄膜層厚さに依存して，その後の熱処理で凝集成長するナノ鉄粒子の分散 状態が変化し, 結果としてその後に成長する MWCNT の成長形態も屈曲したランダム形状から直線状に成長する 形状まで複雑に変化するため, 本試作においては安定して直線状に成長させる条件として膜厚は $5 \mathrm{~nm}$ とした. 膜堆積後に周期的に MWCNT が成長するようエッチング加工を施した.

次に, 熱 CVD(Chemical Vapour Deposition)法を応用して MWCNT を成長させた. 原料ガスには窒素で 18\%に希 䣋したアセチレンガスを使用した。 堆積圧力は $0.1 \mathrm{MPa}$ ，堆積温度は $750^{\circ} \mathrm{C}$ した. 成長した MWCNT の形状と 走查型電子顕微鏡と透過型電子顕微鏡を使用して観察した例を図 4 に示寸. 同図(a)は走査型電子顕微鏡で観察し

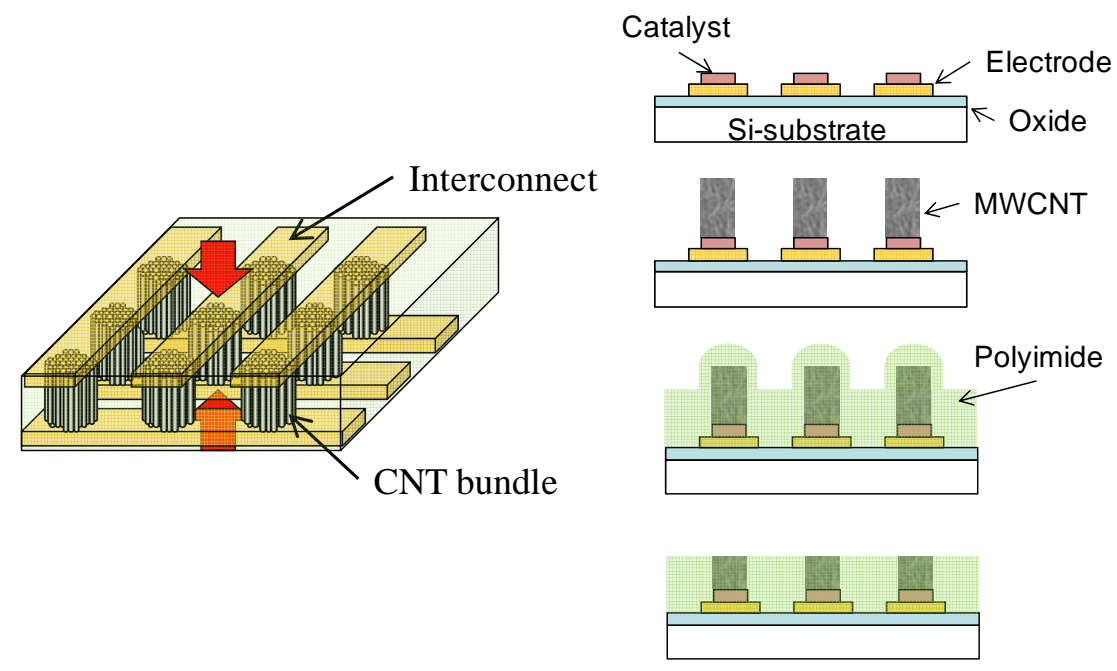

Fig. 3 Schematic diagram of the strain sensor formation process

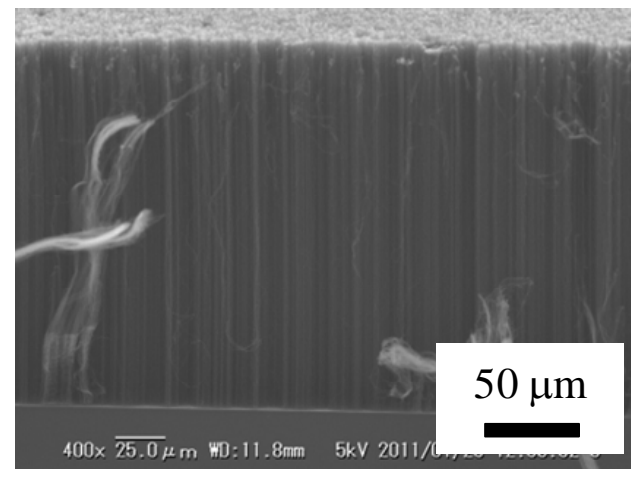

(a) Cross-sectional structure of the bundle of grown CNTs observed by SEM

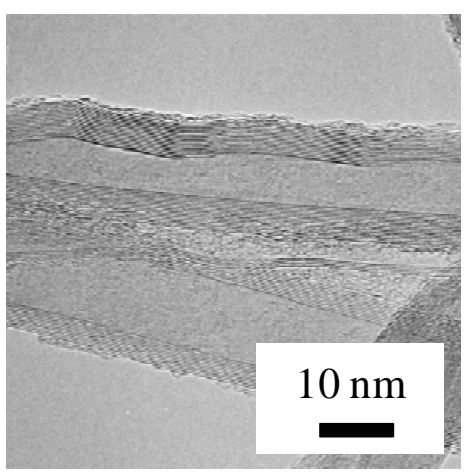

(b) Cross-sectional structure of grown CNTs observed by TEM

Fig. 4 Electron micrographs of the structure of the grown MWCNTs 


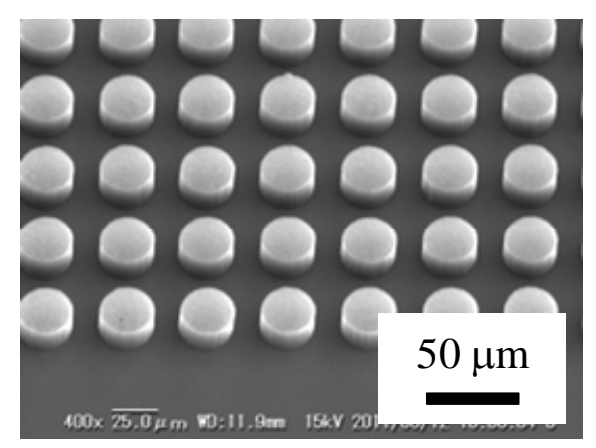

Fig. 5 Outlook of the area-arrayed structure of the grown MWCNTs

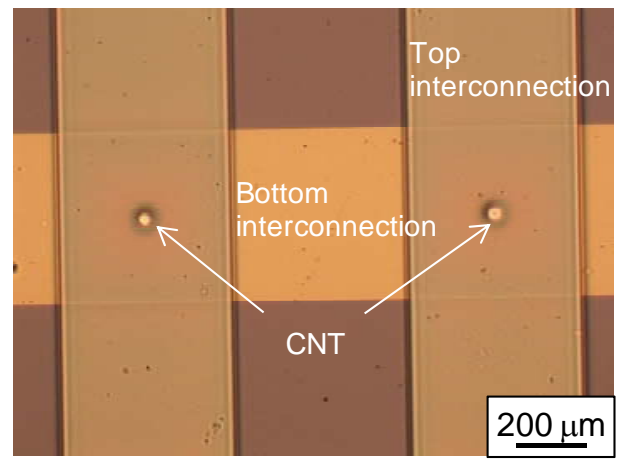

Fig. 7 Outlook of the interconnection structure

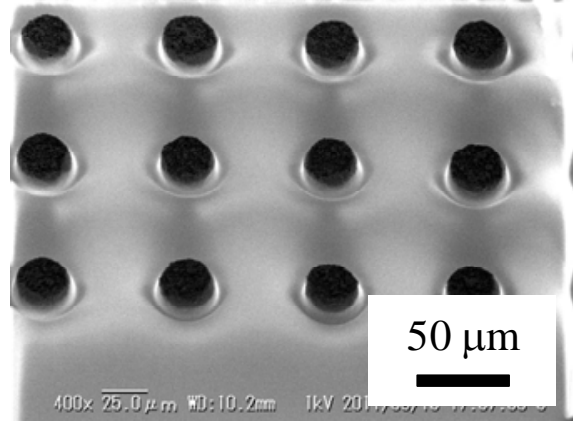

Fig. 6 Outlook of the area-arrayed CNT bundles after the deposition of polyimide

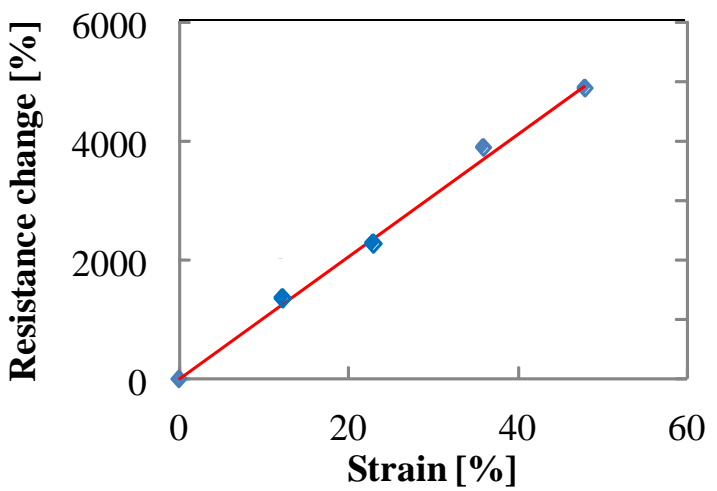

Fig. 8 Resistance change of the bundle of MWCNTs under Compressive strain

た断面構造例で, CNT が約 $250 \mu \mathrm{m}$ の高さで直線状に成長していることが確認された. 同図(b)は透過型電子顕微 鏡を使用した詳細構造観察例であり，成長した CNT が層数約 10 層からなる直径約 $15 \mathrm{~nm}$ の多層 CNT であるこ とを確認した. 図 5 に二次元アレイ状に成長させた MWCNT の外観図を示寸. 直径約 $40 \mu \mathrm{m}$ の MWCNT からな る柱状構造が二次元アレイ状に周期的に成長していることが確認できる.

次に，隣接する MWCNT からなる柱状構造（バンドル）を電気的に絶縁するためポリイミド膜をスピンコート 法で含浸させ，その後熱硬化させた．熱硬化終了後の外観観察例を図 6 に示す．大きなボイド等は残留すること なくMWCNT のバンドル間にポリイミド膜が充填されていることがわかる.この後表面を平坦化するため機械化 学研磨を実施, 表面に上層配線を形成した. 上下配線と MWCNT の接続状態観察例を図 7 に示す. 本試作例では, MWCNT バンドルの直径は約 $40 \mu \mathrm{m}$ で配列周期は約 $1 \mathrm{~mm}$ としている. 本構造における各 MWCNT バンドルの直

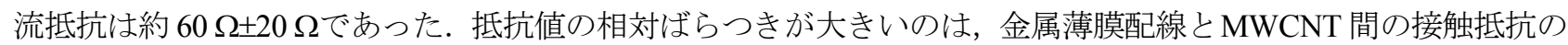
ばらつきと考えており，接触抵抗の制御（安定化）は今後の課題である. この後センサ表面全体に保護膜として ポリイミド膜を堆積した.

\section{4. 試作センサのひずみ検出感度評価}

試作センサ全体に一様な圧縮ひずみを負荷させ，各 MWCNT バンドルの直流抵抗変化を四探針法で測定した. 測定時の電流は $10 \mathrm{~mA}$ 一定とし, 圧縮ひずみ負荷に伴う電圧出力の変動を測定した. 図 8 に抵抗変化測定例を示 す．図の横軸は負荷した圧縮ひずみで，縦軸は初期抵抗で規格化した相対抵抗変動率である．本測定例では，抵 抗值は負荷ひずみにほぼ比例して単調に増加することを確認した．負荷ひずみに対する抵抗の変化率，すなわち ひずみゲージのゲージ率として約 100 が得られた。 しかし, 現状ではこの応答特性にも MWCNT バンドル間に個 体ばらつきが認められた，その主要因は，負荷の開始直後から直ちに抵抗変化が現れず，所定の負荷ひずみ以上 の範囲で線形特性が発現したというものである.この原因としては金属薄膜配線と MWCNT 間の電気的な接触の 
不安定性が考えられ, 安定したオーミック接触を得るためにある程度の押圧が必要になるような不安定接触箇所 があったためと考えられる。これは上述した接触抵抗の不安定性にも現れているものと考えており，センサ特性 の安定化を図るには，やはり金属薄膜配線とMWCNT 間の接触抵抗の制御が不可欠と考えられる．ただし，本評 価結果から，超高感度の圧力分布センサの実現可能性が示されたものと考えている.

\section{5. 結 言}

多層 CNT を二次元アレイ状に配列させた二次元ひずみ分布センサを薄膜プロセスを応用して試作した．第一 原理解析に基づき, CNT を構成する炭素六員環が異方的に変形することで, 電子バンド構造が複雑に変化し, 電 気伝導特性が金属的な伝導特性から半導体的な伝導特性の間で変動し，大きな抵抗率変化が生じる可能性が示さ れた. 本解析も踏まえ, 高さ約 $250 \mu \mathrm{m}$ の多層 CNT を直径約 $40 \mu \mathrm{m}$ の柱状構造からなるバンドル構造として周期 約 $1 \mathrm{~mm}$ で熱化学気相蒸着法を応用して成長させ, リフトオフ法を応用して二次元配線構造を作製することで, 二次元ひずみ分布計測を可能とする構造を作製した，本センサの面厚方向に圧縮ひずみを作用させたところ，多 層 CNT バンドルの直流抵抗值が負荷ひずみにほぼ比例して増加し，そのゲージ率として最大約 100 が得られた ことから，超高感度の圧力分布センサの実現可能性が示された.

\section{文献}

(1) Dharap, P., Li, Z., Nagarajaiah, S. and Barrera, E.V., "Nanotube film based on single-wall carbon nanotubes for strain sensing”, Nanotechnology, Vol. 15, (2004), pp. 379-382.

(2) Kang, I., Schulz, M.J., Kim, J.H., Shanov, V. and Shi, D., “A carbon nanotube strain sensor for structural health monitoring”, Smart Material Structures, Vol. 15, (2006), pp. 737-748.

(3) Zhang, W., Suhr, J. and Koratkar, N., "Carbon Nanotube/Polycarbonate Composites as Multifunctional Strain Sensors", Nanoscience and Nanotechnology, Vol. 6, (2006), pp. 960-964.

(4) Lu, J.W., Wang, W.L., Liao, K.J. and Wan, B.Y., "Strain-Induced Resistance Changes of Carbon Nanotube Films", International Journal of Modern Physics B, Vol. 19, (2005), pp. 627-629.

(5) Okada, S. and Oshiyama, A., "Curvature-Induced Metallization of Double-Walled Semiconducting Zigzag Carbon Nanotubes”, Physical Review Letters, Vol. 91, (2003), pp. 216801.

(6) Saito, R., Dresselhaus, G. and Dresselhaus, M.S., "Electronic structure of double - layer graphene tubules”, Apply Physics, Vol. 73, (1993), pp. 494-500.

(7) Hu, N., Fukunaga, H., Lu, C., Kameyama, M. and Yan, B., "Prediction of elastic properties of carbon nanotube reinforced composites", Proceedings of the royal society A, Vol. 461, (2005), pp. 1685-1710

(8) Liu, Y.J., and Chen, X.L., "Evaluations of the effective material properties of carbon nanotube-based composites using a nanoscale representative volume element”, Mechanics of Materials, Vol. 35, (2003), pp. 69-81

(9) Hu, N., Karube, Y., Yan, C., Masuda, Z. and Fukunaga, H., “Tunneling effect in a polymer/carbon nanotube nanocomposite strain sensor”, Acta Materialia, Vol. 56, (2008), pp. 2929-2936.

(10) Hu, N., Masuda, Z., Yan, Z., Yamamoto, G., Fukunaga, H. and Hashida, T., "The electrical properties of polymer nanocomposites with carbon nanotube fillers”, Nanotechnology, Vol. 19, (2008), pp. 215701.

(11) K. Osaki, H. Fuji, M. Onishi, K. Suzuki, and H. Miura, "REMOTE STRAIN MEASUREMENT BY MULTI-WALLED CARBON NANOTUBE-DISPERSED RESIN", Proceedings of the ASME 2009 Inter PACK Conference, No. 89146, (2009), pp. 1-7.

(12) Y. Ohashi, Y. Suzuki, M. Ohnishi, K. Suuzki, and H. Miura, "Non-Contact and Remote Measurement Method of the Change of the Electrical Conductivity of Carbon Nanotubes-Dispersed Resin under Strain", Proceedings of the ASME 2011 Inter PACK Conference, No. 52064, (2011), pp. 1-6.

(13) 大西正人, 鈴木研, 三浦英生, “グラフェンシートの電気伝導特性に及ぼすひずみの影響” 第23回計算力学講演会 講演論文集，(2010), pp.441-442.

(14) M. Ohnishi, K. Suuzki, and H. Miura, "Change of the electronic conductivity of carbon nanotube and graphene sheets caused by a three-dimensional strain field”, Proceedings of the ASME 2011 Inter PACK Conference, No. 52057, (2011), pp. 1-6.

(15) M. Ohnishi, K. Suuzki, and H. Miura, "Strain dependence of the electronic conductivity of carbon nanotubes and graphene sheets”, Extended abstract of the 2011 Int. Conf. on Solid State Devices and Materials, (2011), pp. 508-509. 